\title{
Skin Stories \& Skin Portraits
}

\author{
Tanny Dobbelaar \\ University of Groningen, The Netherlands
}

This skin is me, I can't get out ${ }^{1}$

What personal stories do people with a chronic skin disease have to tell? This was my main question in 2001 when I initiated the project "Heftig Vel", which could be translated from Dutch as "Severe Skin".

At the start of the project my supposition was that people with a skin disease had but two main narratives at their disposal: the first being the medical narrative of their doctors which refers to skin conditions, the malfunctions of the skin, the different appearances and, if at all known, the underlying causes.

Many of these conditions are described as being the result of genetic defects or autoimmune diseases. Treatment consists mainly of combating the symptoms of the disease with medications that have serious side effects. Most patients know that they can only hope for an adequate treatment in the far future and must for the time being simply 'learn to live with it'.

These medical narratives can be found in medical journals, universities and hospitals. (During my research I even found a bizarre website that documents the scars, traces of acne and dermatitis, birth marks, spots and other dermatological phenomena on the skin of well-known actors and pop stars, as well as on the skin of the personalities they inhabit on screen and stage. ${ }^{2}$ )

Usually these narratives are accompanied by clinical descriptions of the symptoms and, of course, through pictures of the body parts where the disease is present. The owner of the displayed skin is most often hidden, the standard practice being to cover the face with a black bar in order to prevent recognition. In these pictures the disease is completely objectified. 
Although this whole package of dermatological language and visualizations has a long, very interesting and specific history, it is clear that it has almost nothing to say about the personal day-to-day experiences of living with a difficult skin. ${ }^{3}$ The same is true for the so-called 'quality-of-life reports' that paradoxically give the results of quantitative research about diverse social and psychological aspects of living with a skin disease. They only serve to further objectify the struggles reported by patients, e.g. the risks of psychiatric symptoms such as depression, suicide, addictions and anxiety among psoriasis patients. ${ }^{4}$

These 'quality-of-life' reports are more frequently associated with the second main narrative that skin patients use to describe living with a difficult skin, a narrative that could be called, in none too subtle terms, as the complaining narrative. This is the narrative of subjects who have little or no control over their lives and can only speak about the physical pain and the distortions of their lives, the depressions and feelings of self-loathing, along with the social exclusion that often accompanies having a skin disease.

The complaining narrative has the same disadvantages as the medical narrative: the skin disease itself appears in this narrative unequivocally as an unwanted cause of trouble. And it offers very few clues as to possible ways of integrating the disease with life itself. Do skin patients have an alternative to these two dominant narratives? Think of what John Updike wrote about his psoriasis: 'This skin is me, I can't get out'.

When I became a skin patient myself with, in hindsight, a temporary outburst of dermatitis - I could not walk and I could not bathe, I could not even write because of the deep cracks in my hands. I was desperate, not only because of the way I looked and the impact that dermatitis was having on my life, I could not, first and foremost, express myself any more. This in turn led to a strong wish to make sense of the situation I had been dropped into.

I both admired and envied how Dennis Potter used his own experiences with severe rheumatic psoriasis to create The Singing Detective: a wildly praised television series, a blend of drama, film noir and musical, where the main character is hallucinating from the pain of his psoriatic arthritis in his hospital room. He experiences flashbacks from his childhood and he also gets fantasies about the novel he is trying to write. ${ }^{5}$

With the same mixture of admiration and envy I read John Updike who had written beautifully about the influence his psoriasis had on his life as a writer, on his marriages and on the relationship with his body. ${ }^{6}$ 
They however, were artists and I was just a freelance journalist with an education in Philosophy and a painful condition and a miserable appearance.

Thomas Couser rightly criticized the idea that one's identity, politics and I would add - affinities are, or ought to be based on shared attributes such as ethnicity, gender, illness or disability. ${ }^{7}$ Nevertheless, I had a strong personal motivation to identify with other skin patients and their stories. How do they make sense of their chronic skin disease? This question became a starting point for this project: I wanted to collect stories about skin diseases that did not neatly fit into the medical narrative or the complaining narrative of the victims. Moreover, I had this strong desire to create something out of this misery: contact with peers was, at least for me, not enough.

'Skin' has strong cultural associations with sex, beauty and health. Because of these associations, I also started dreaming about an exhibition where the skin stories would be accompanied by beautiful photos of the interviewees.

And with 'beautiful' I referred vaguely in those days to an new imagery, a series of photographs that would offer an alternative to the medical visual culture of dermatologists, as well as to the metaphorical use of an imperfect skin by media when depicting the monstrous, the freakish or the criminal. Instead, I imagined a visual imagery where the interviewees as subjects would, first and foremost, be truly seen as humans with their scars and imperfections, without the stigma of being a skin patient.

Luckily, the first photographer I discussed my ideas with, Adrienne M. Norman, understood my intentions immediately. In the two years we worked together on this project, we spoke with many skin patients who were all very willing to tell us about their lives. They posed patiently before the camera and didn't hesitate to show their faces and their bodies.

Adrienne and I both felt that we were attacking the 'culture of camouflage', as one of the interviewees so aptly put it. We really tried to express the experiences of the participants. I chose a specific form: I interviewed the participants for two hours and afterwards distilled their stories into one very short text of 150-200 words. Needless to say that I asked all of the participants if they agreed with my particular transcription of their subjectivity: they all did.

While working on the project I discovered that the participants all made use of the two main narratives I mentioned earlier: they could not, as I 
had hoped, escape them, but rather mixed them together in a very personal and unique assemblage, in stories with a particular interpretation of the meaning of the disease in their lives.

The photographer also struggled deeply with the question of how to visualize the subjective side of skin diseases. In one of her grant application letters for this project she framed this question as a justification of her choice to use colour photography instead of black and white. She wrote:

"At first glance my portraits may come across as medical photography and not portraits of individuals. This first impression is inherent to the subject and the perception that we may have of what a photographic image should look like. The beauty of a photograph itself can be reassuring or comforting, no matter who or what is represented.

I have this feeling when looking at the black and white photographic illustrations in medical handbooks from the 19th century. The timeless quality of the black and white image is so beautiful, that it's not even about the subject. The photo itself is beautiful. This is what I mean when saying that a photo can create a comforting feeling. Partially because of this I had originally wanted to photograph skin patients in black and white.

Initially I struggled while making these portraits, not only because of confronting appearances, but also with my approach as a photographer. Is it about the beauty of a photo, or is about what I see?

What I see is that for some skin patients, their skin is an almost apart entity. It is difficult for people to deal with their skin affliction, physically and emotionally. It is painful to have an outward appearance that does not always represent what you want to show others. Skin patients generally want to hide their less attractive appearance. I ask them to show it.

Ultimately it was the models themselves who gave me the freedom and courage to make these portraits. My challenge was to create photographic images that are inviting to look at, despite the absence of any conventional forms of beauty. I wanted to discover what there is to see behind the raw, painful and at times confronting appearances. Photographing this in black and white ignored, in my view, the reality of the individuals. For this reason I chose to photograph in colour."

What began as a naïve personal question in search of knowledge was in the end received as an art project. ${ }^{8}$ More than ten years later, and lecturing in Oral History at the university, I see many connections with Life 
Writing and Disability Studies. At that time I didn't know of any academic discussions among oral historians about storytelling and narratives, nor was I aware of the theoretical questions around Life Writing. Only ten years later, when I was asked to train people in writing essays on Disability Studies, did I find the same motivations among these scientists as I had while working on this project. They all wanted to study the experiences of people without objectifying them.

In this essay I would like to show to an international academic public a selection of what we, Adrienne Norman and I, tried to communicate at that time through a highly hybrid project that has many sides to it. The selection starts with the preface of the book, which was specially designed to enhance the experiences of the subjects in the eyes the viewer. All of the portraits are wrapped in opaque paper using the so-called Japanese book binding method. One has to use a knife to cut the paper and 'free' the portrayed people from their outer packaging in order to see them and read the interviews. Once you have uncovered the paper, you cannot undo the tears in the paper, as you cannot undo the traces of time on your skin. Something has happened between you, the reader, and the people in the book: the binding paper with its cracks is your personal witness. ${ }^{9}$

The preface of the book will be followed here by several Skin Portraits \& Stories of the participants.

\section{PREFACE}

"From the corner of your eye you see a stranger. Unintentionally your attention is drawn. You take a look. Just for a second, a thousandth of a second. Too long! Don't look. It's improper. Looking away always happens too late. The person in question knows that he or she is being looked at. It is an uncomfortable confrontation, unwanted by both parties. With a blank stare you each go your own way.

"This skin is me, I can't get out". The people portrayed in Skin Portraits are used to being looked at. They are prisoners within a skin that constantly flakes, hurts, and itches. Their outward appearance does not represent their inner self. They have no control over how others see them, how others fantasize about them. Interactions are hasty and there is no defence.

The people portrayed here give you their permission. You may look, neither secretively nor as a voyeur from the corner of your eye who is afraid of being caught. You may look as long and as intensely as you like. With full attention and straight in the eye." 


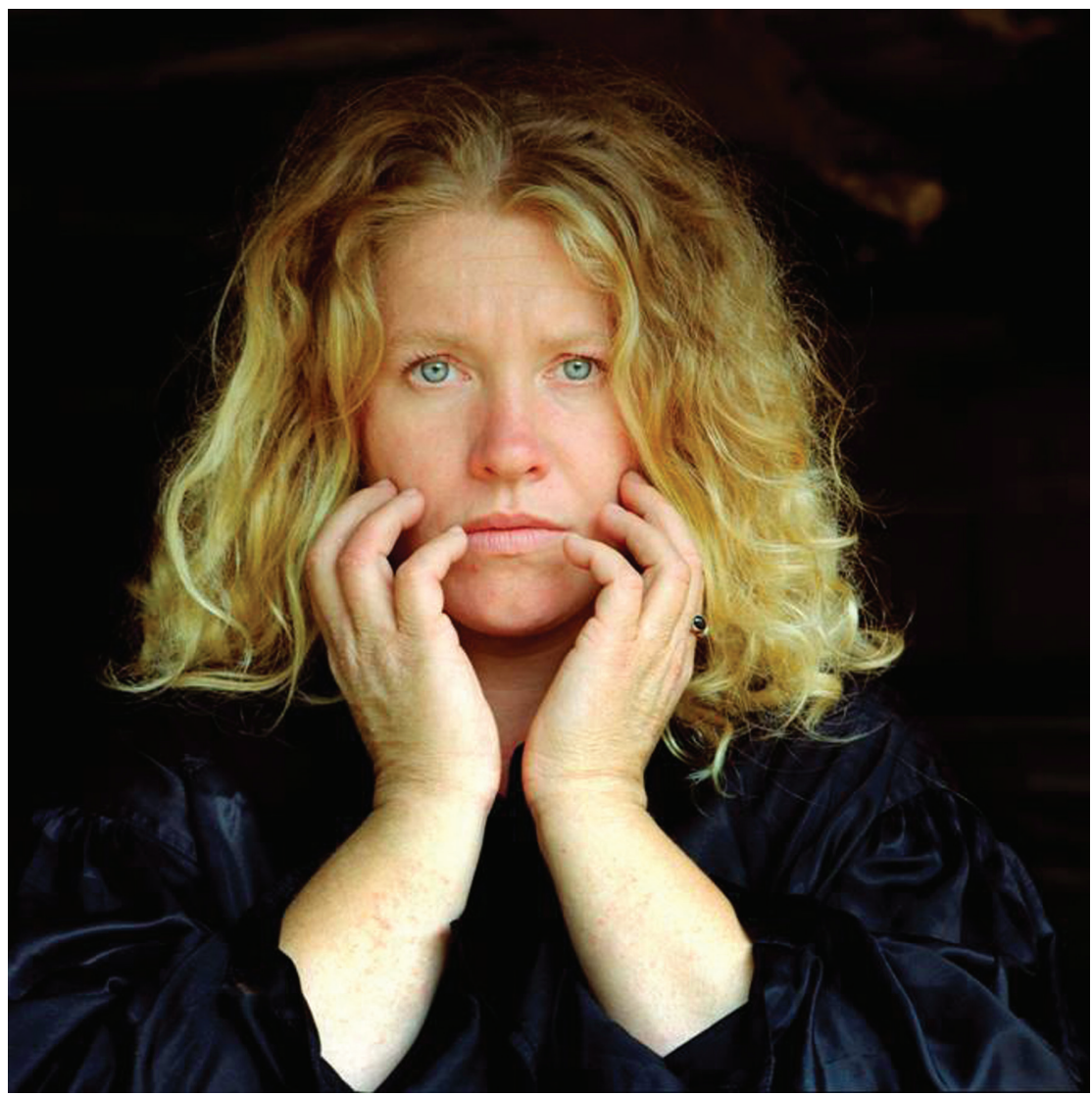

Since my childhood I have been caught up by the story of the little mermaid. She is a monster with a fish tail that falls in love with a human prince.

She goes to the witch and asks her: give me human legs.

I have always felt like the mermaid. My skin also has scales and I know, I know that the sea is good for me.

The witch in the fairytale says: fine, I will give you legs, but each step that you take will be as if knives are cutting into your feet, and you are not allowed to talk about it.

The mermaid accepts this. Nobody knows how much pain she has.

My body and I are in constant battle. The constant itching that no one sees. An itch is a tirade. Try and sit still so that no one notices. It costs a mountain of energy.

Jessica 


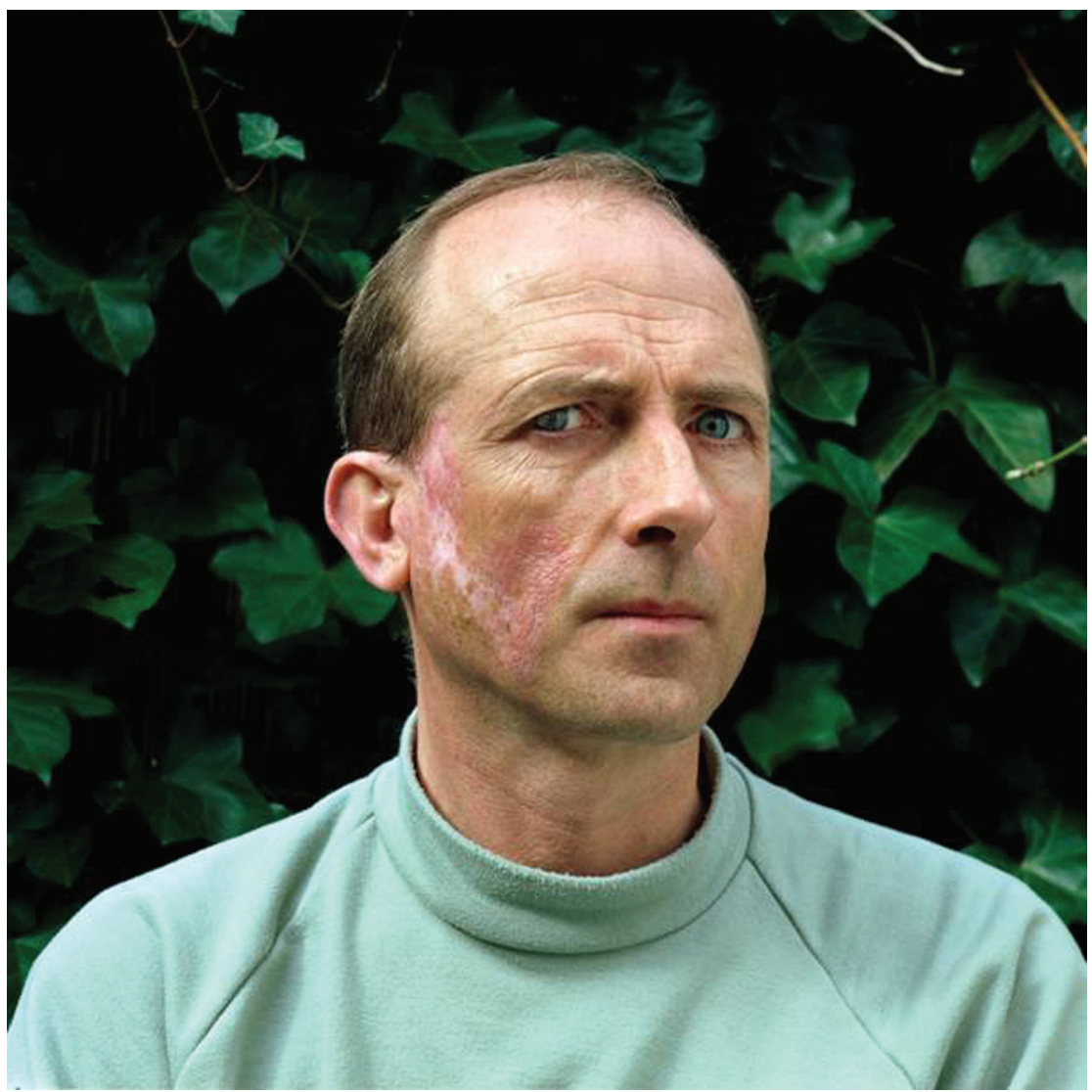

In the photograph I see a reproachful, mistrustful look. You need to get behind the outside to find out what is inside. The fact is my life started with a lot of pain. I see that when I look at this picture. A sort of dissatisfaction, as if I can't quite get it together.

At thirty I was admitted. It lasted one and a half years. After therapy I started life again. I had no work, no relationship, and was alone in the city. At this time I got lupus erythematosus (LE), at first it was a dark red band on my arm and back, later it turned into spots on my face.

The LE can be handled, but not cured. I have come to terms with this, just as I have come to terms with my past. I was an old man. Until my thirtieth I was a moralist who knew how the world was. Now I am open for what life has to offer me.

Rini 


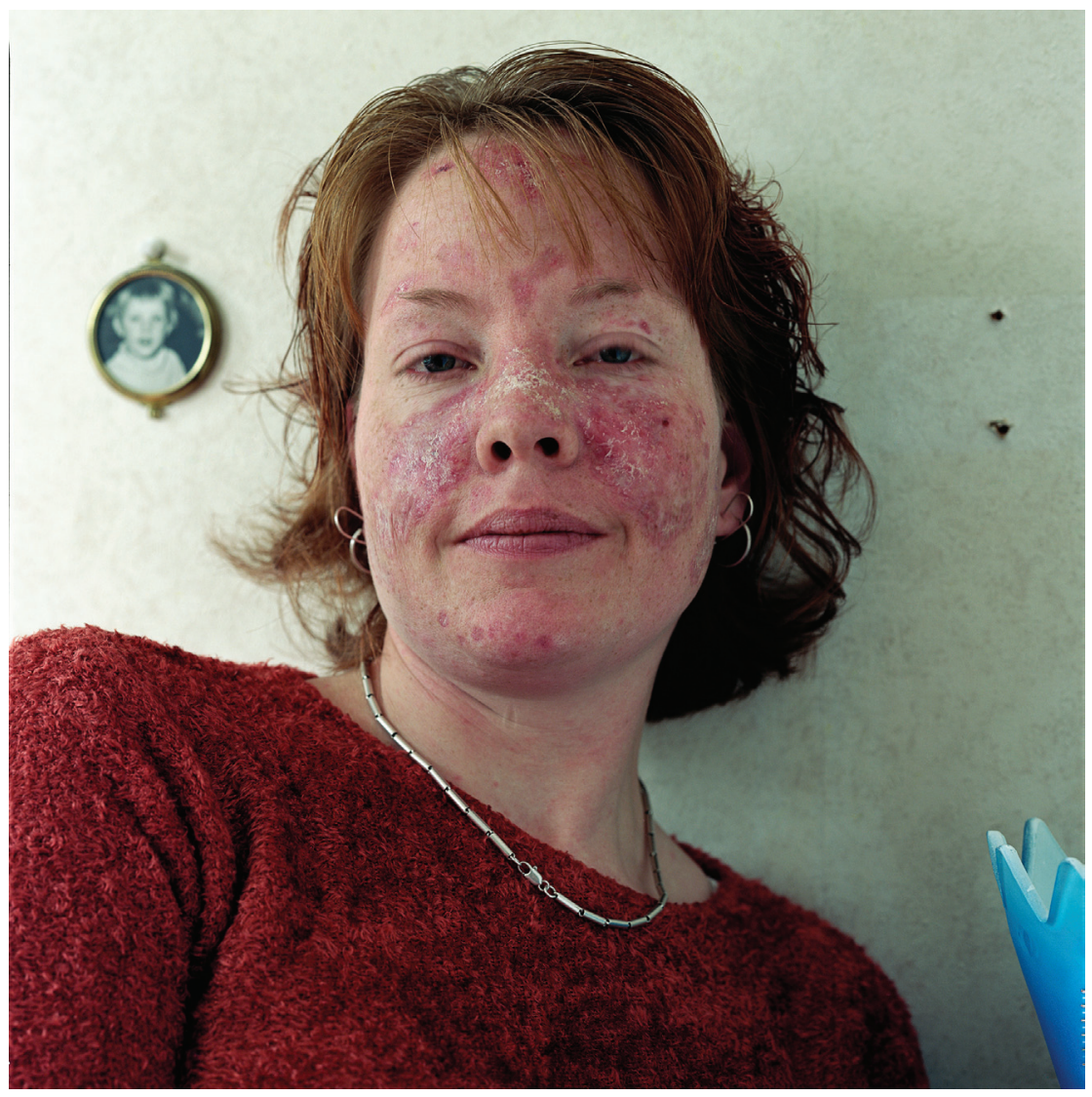

Without even asking me doctors have a ready diagnosis: "oh, eczema". At the drug store pots of cream are pushed into my hands. In the supermarket I hear them whispering: "she has AIDS".

This affects me enormously.

What helps is having contact with others in the same position. I once met another systemic lupus erythematosus (SLE) patient in the waiting room. You recognize the spots, a kind of butterfly form. We stared at one another intensely, faces close to one another. That was special.

For me it is all or nothing. This works out with my sickness. One day I am sinking through my knees, the next day everything is fine. Today I look good, but at other times my whole face is infected. Of course, you keep hoping for a cure. I have tried the strangest tea concoctions, have had my face injected with prednisone. Nothing helps.

Miranda 


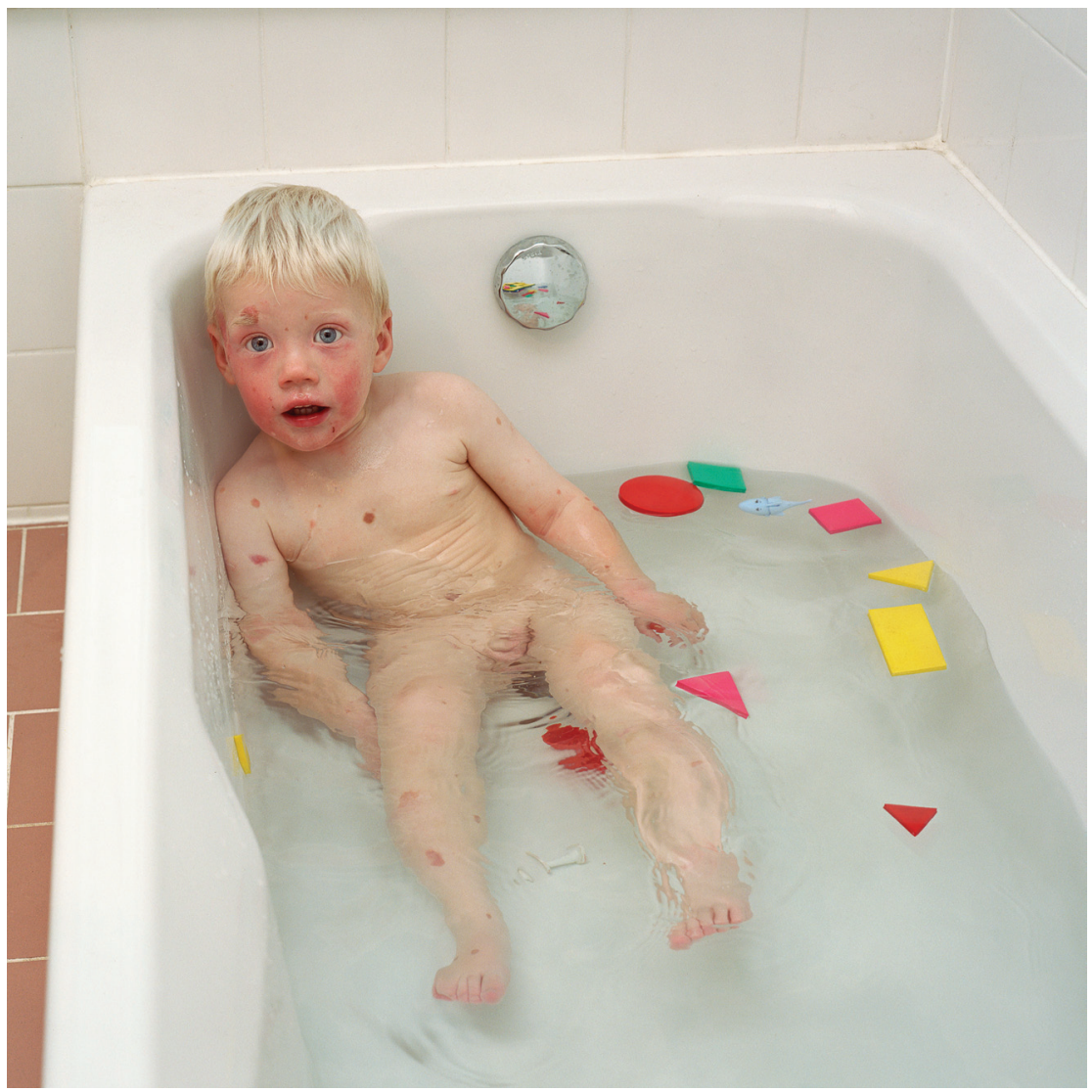

Marjolein, mother of Dafnis:

"When Dafnis was born, I couldn't bond with him. I did not know if he would survive. He had large black birthmarks all over his little body and face. The largest mark covered his lower back. Something like this cannot be seen on an echo.

He was operated on three times within the first twelve weeks of his life. After the second operation he got eczema. And after the third operation he contracted a lung infection. He stopped breathing and turned blue. When he came to life, I knew: I will never let this child go. We had a difficult start. Only since his second year can I enjoy him fully. Dafnis is a very special child."

Dafnis 


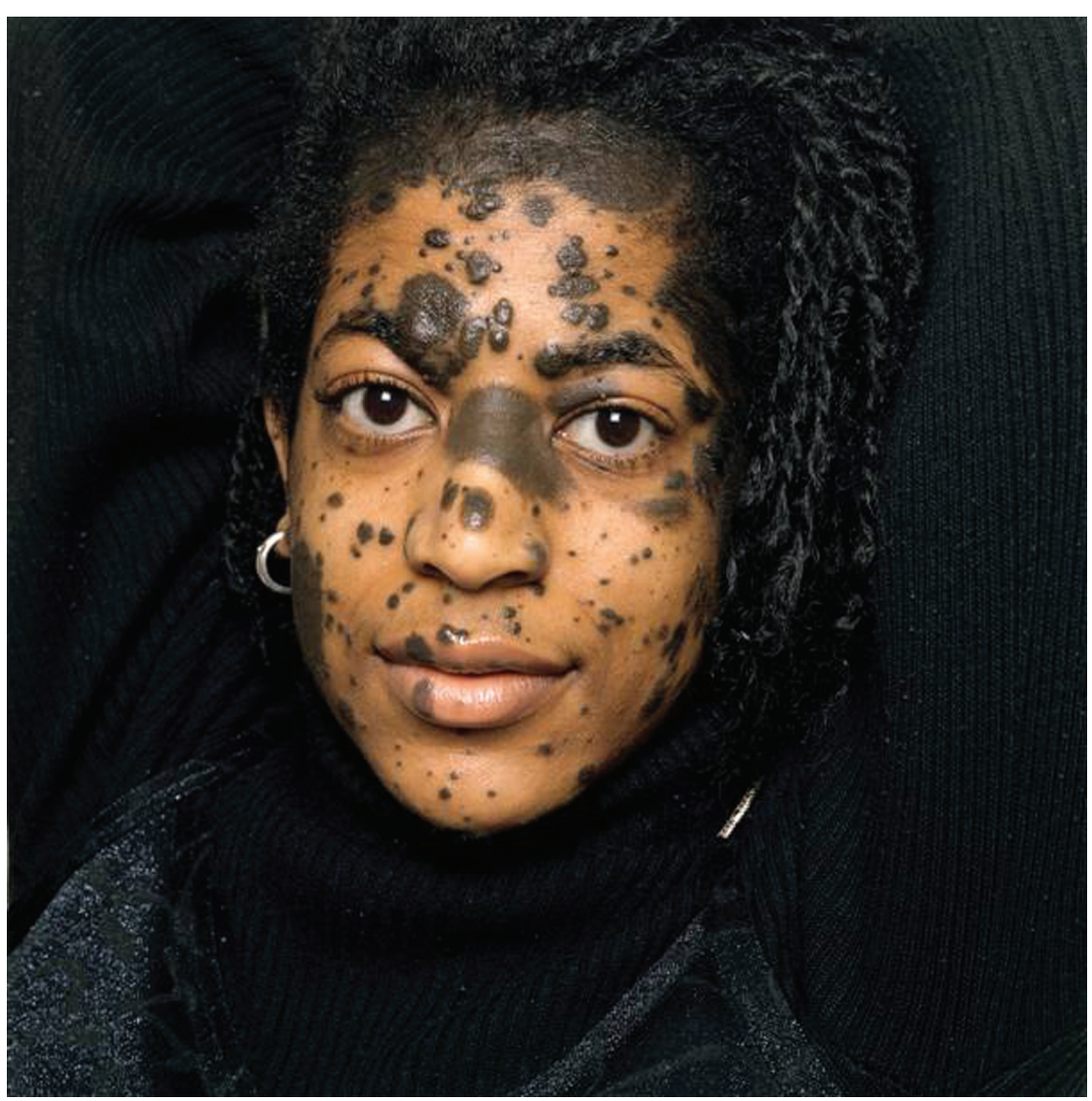

I have something without a name, spots, neuro fibers and swellings. No doctor can do anything for me.

My body used to be my enemy, now I try and love my body as much as possible. I can feel if a swelling is malignant. Recently I had one in my breast. If they feel fine, I leave them. This one worried me. The doctor did not believe me. I kept at it though. I was not surprised. I am always right. Now if I feel something, I do not need to have it tested. The doctor said: you know your body so well. If it is necessary, just go directly to the operation room.

Naomi 


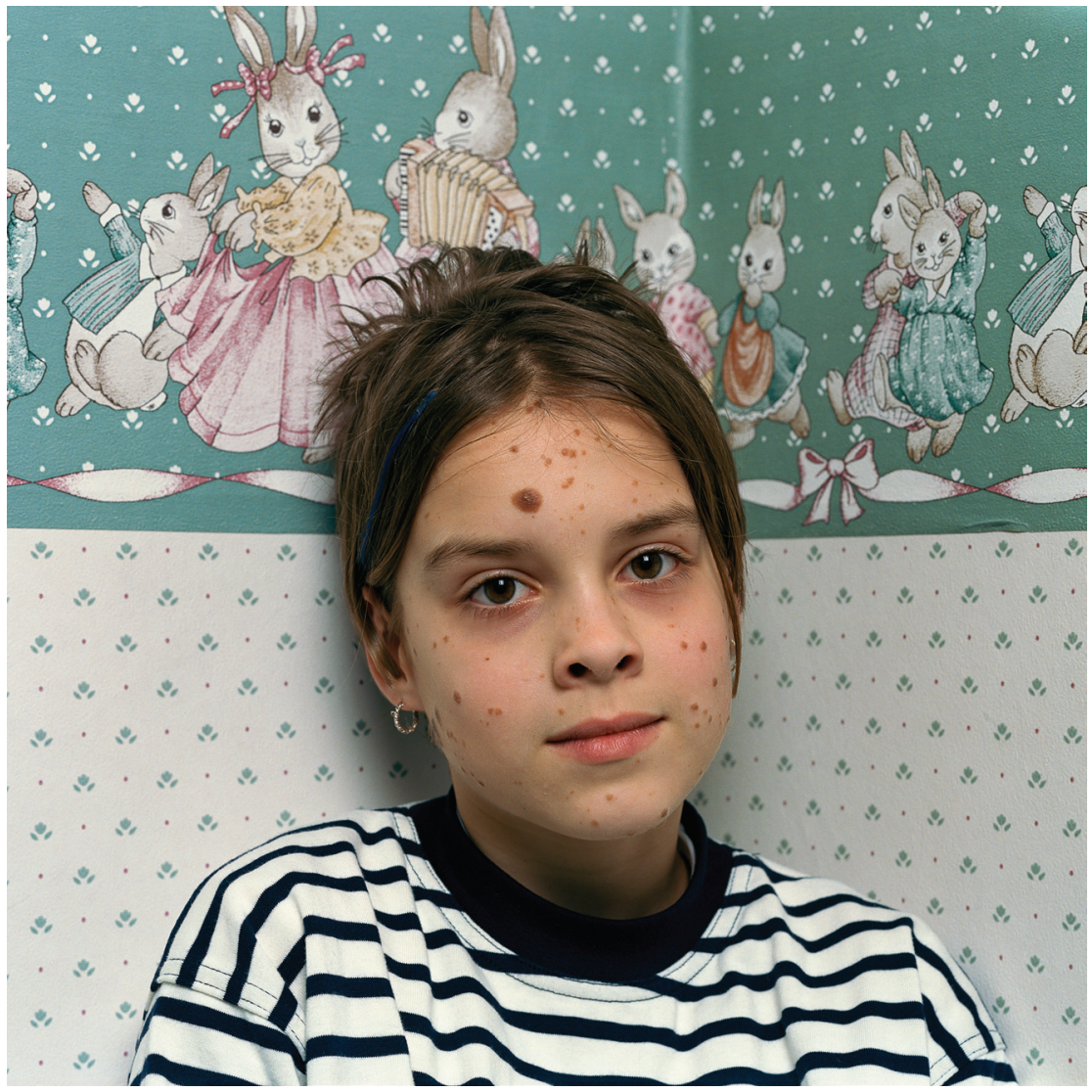

Seventy percent of my skin is covered in birthmarks. On my arms, legs and face I have a lot of small birthmarks. My stomach and back is one big birthmark.

That is the way I was born. I am the oldest of triplets; my two little brothers do not have anything. When I see baby pictures of myself, I sometimes think: was that me? Back then my skin was fat and wrinkly. And I had a large bump on my back. The lump has been removed, it really looked scary.

My parents have thought about skin transplants. The scars however, are uglier than the birthmarks. Now I think: the marks are a part of me. I used to say: mama, if all my marks are gone, then nobody will recognize me anymore.

Mariko 


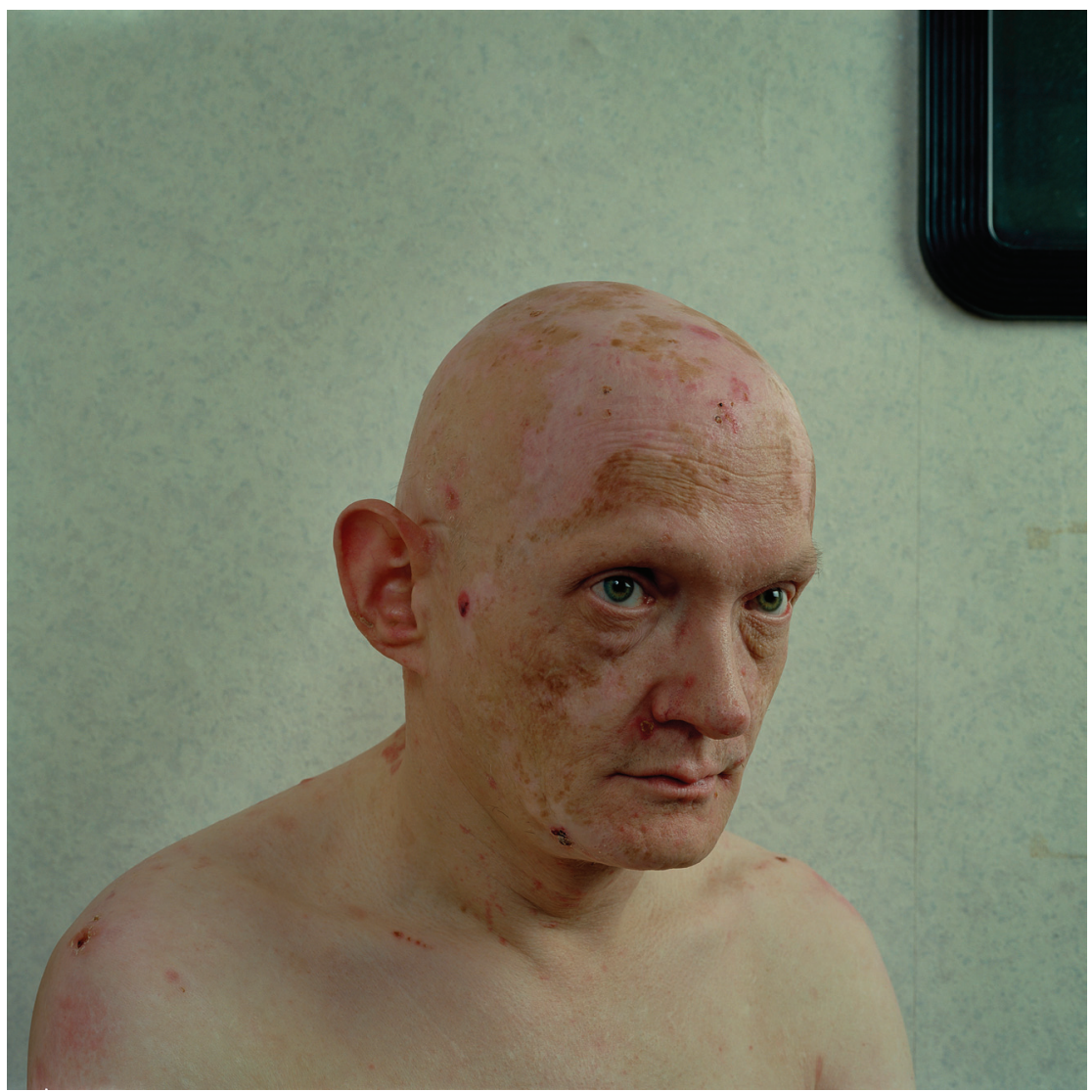

A person can wound me by just touching me softly, that is how quickly my skin breaks. At birth I was already partially skinless. In the baby-box I was still, moving was too painful. I spent my youth in a bandage. Because of this my development was severely affected. At times I feel nothing.

Twelve cases of arson are attributed to me - no deaths or injuries occurred. I started the fires with a clear head. Whole buildings exploded before my eyes - it was very arousing.

During rehabilitation a possible link between the fires and a longing for physical warmth was suggested, at the time I did not want to consider this, now I understand the connection. I have been out of rehabilitation for ten years. From time to time I have physical contact with a woman. If only I had discovered this earlier, a lot of pain could have been prevented. Lex 


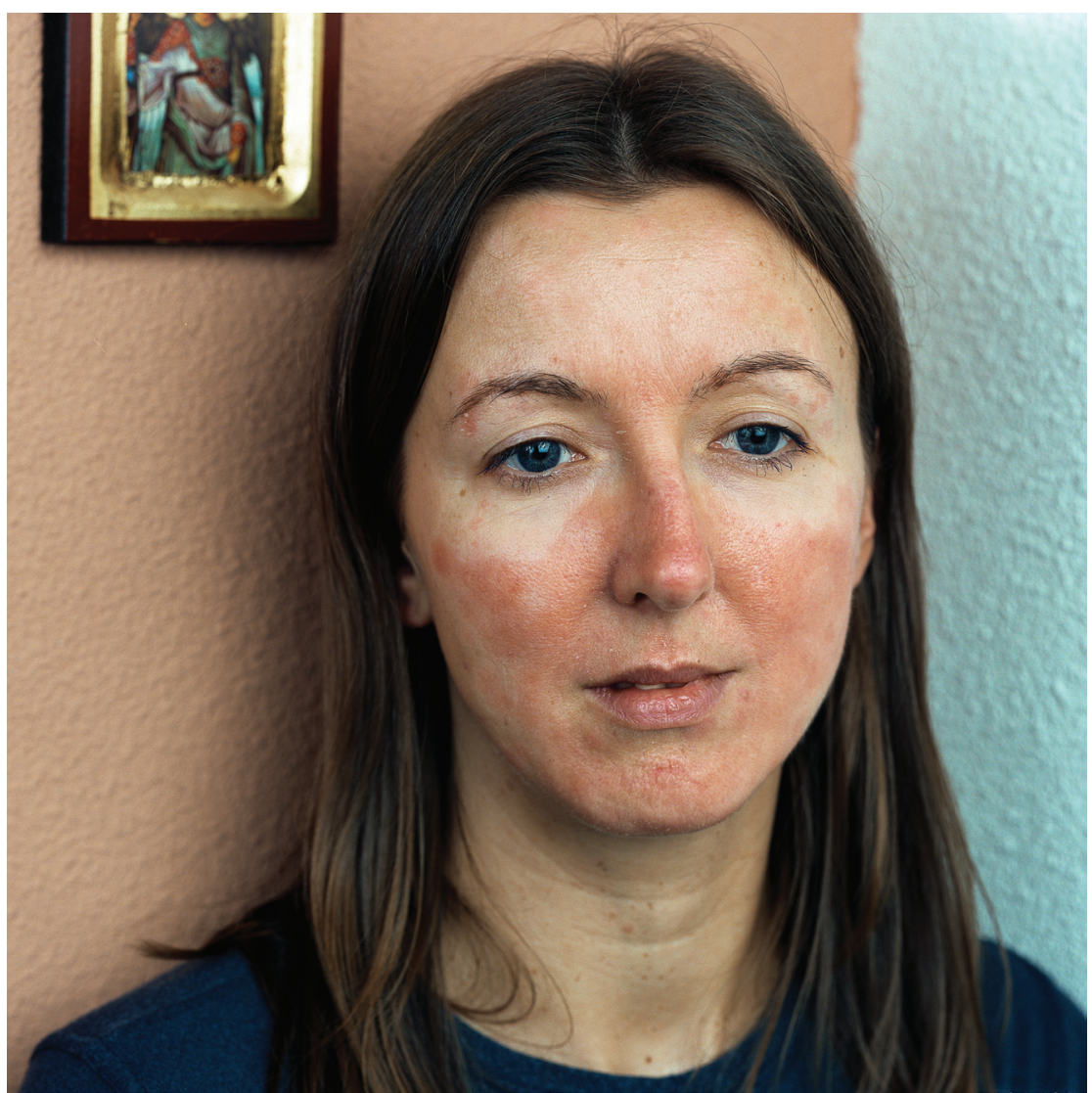

Sometimes in a rage I think: give me the cheese knife, I want to be rid of these spots. I also want a smooth skin.

I cannot accept what I have. They call it Acne rosacea. Honestly, I don't even want to accept it. God wants us to be healthy. I just know for sure that one day, maybe after a long time, that I will be a complete person: sound of body and soul.

I know my spots intimately. Without a mirror I can point them out. My skin is for the people around me a side issue. For me they are a main issue, even though I know that I am not ugly. In spite of my illness I do have a nice skin.

Carin 


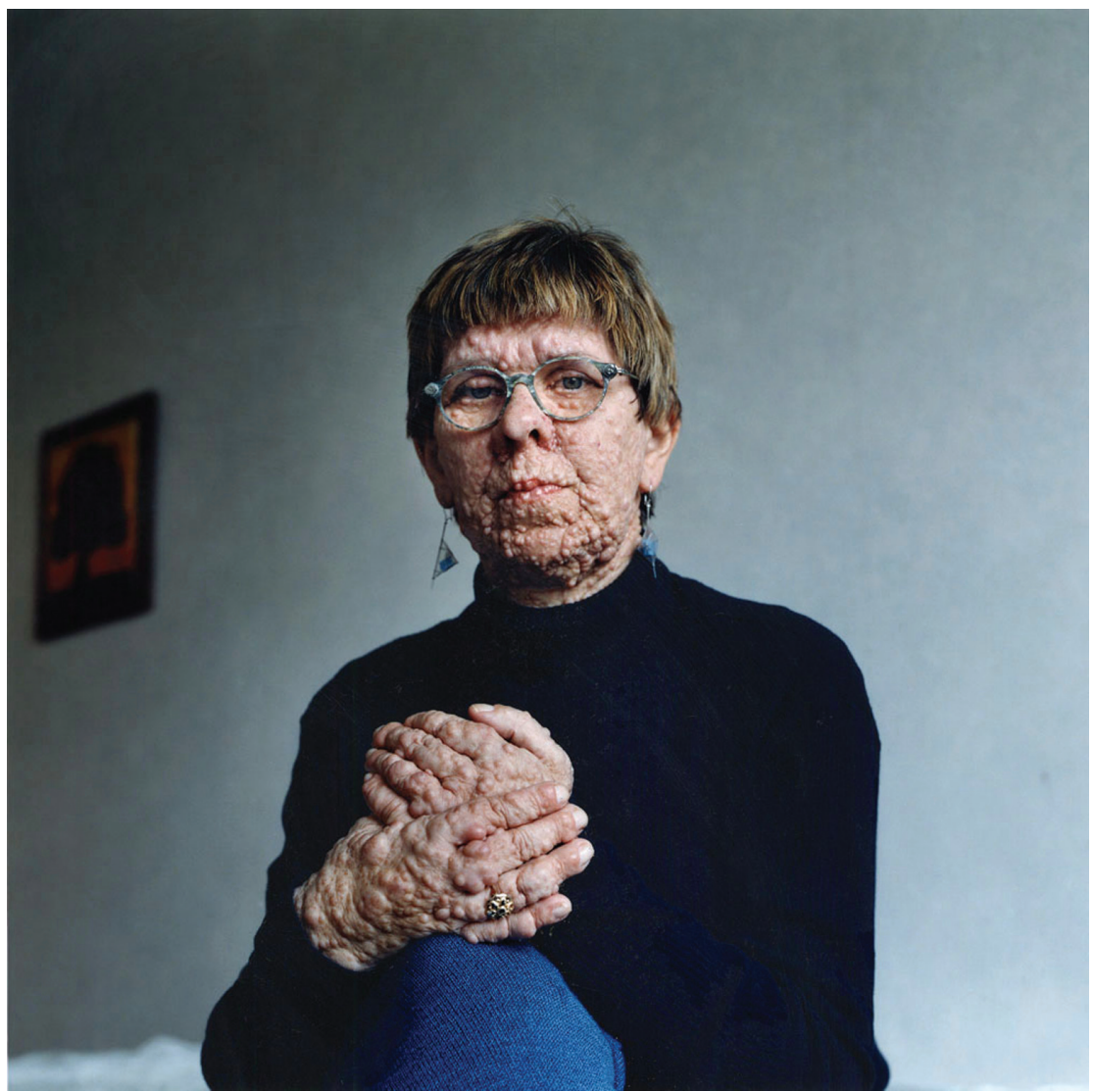

Just by a hand shake I can tell how a person is judging me. If it is a firm hand, I know: they accept me. They have courage. At a weak hand, I think: bah, another person who is afraid of me.

My first bubble appeared when I was seven. At the age when you want to start dating a lot of bubbles appeared. I once took dance lessons, and I still looked good enough to be asked.

I am alert and down to earth. This illness has of course defined a large part of my life. It is not out of choice that I live alone, with no family.

My life is however active. I go on vacation, love driving, work five days a week in a bank. People do not expect this of me. I continuously have to prove myself, and this saddens me deeply.

Elly 


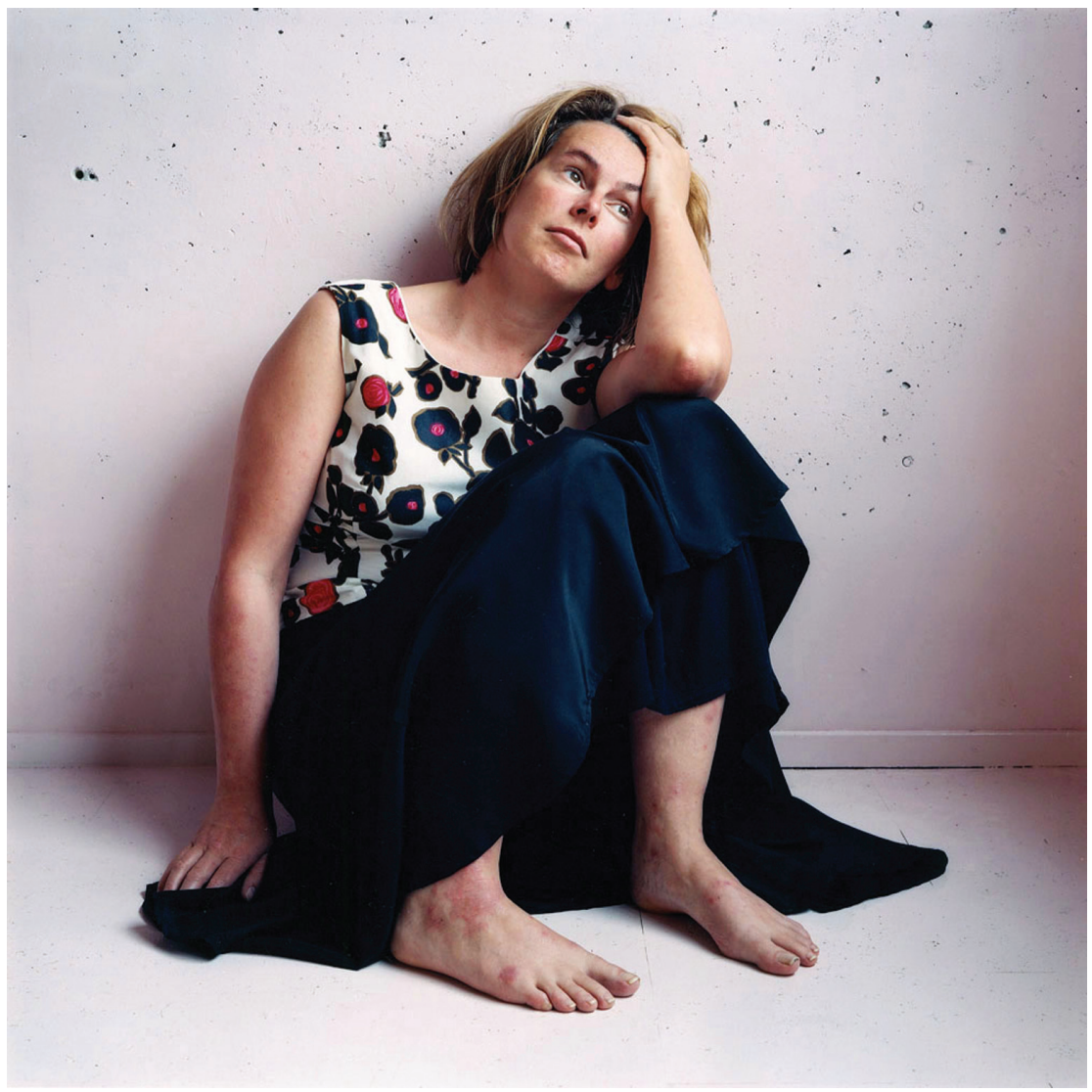

I am very esthetically oriented; I want to make things beautiful. My skin is ugly, but I try to use this by making my own special attire, from thin subtle materials.

Because I am so esthetically inclined, magazines that show only perfect people really angers me. Western people are becoming more and more estranged from themselves. In Africa every thing is on the street: people with blisters and crippled legs are a daily part of life. With us everything that is aberrant is hidden away.

If you have a pretty face, you can get away with more. I was quite pretty before the red cones started appearing on my face at twenty-one. CDLE it's called. At thirty the psoriasis showed up. I really had to change gears when my appearance changed. Receiving attention was no longer a given. Still, I have never been rejected because of spots. One time I was lying on the beach sunbathing. A very handsome guy came up to me and asked 
what I had. He was a medical student. We spent the whole afternoon kissing. He found me very interesting. I guess I was something different. Liesbet

\section{ABOUT THE AUTHOR AND THE PHOTOGRAPHER}

Tanny Dobbelaar studied Philosophy and Journalism. She is currently working on an $\mathrm{PhD}$ about recent family histories at the University of Groningen, The Netherlands. a.j.c.dobbelaar@rug.nl

Adrienne M. Norman works as an independent portrait and documentary photographer, based in Amsterdam, The Netherlands. To see more of Adrienne's work visit her site www.amnorman.nl

\section{NOTES}

1 See 'At war with my skin', in Updike, John Self-consciousness. Memoirs. (London: Deutsch, 1989), p. 72 (note).

2 See http://www.skinema.com/.

3 See for instance the Doctoral Theses of Mineke ten Hennepe (2007), Depicting Skin: Visual Culture in Nineteenth Century Medicine, University of Maastricht, The Netherlands.

4 See for instance Kurd SK et al. 'The risk of depression, anxiety, and suicidality in patients with psoriasis: A population-based cohort study'. Arch Dermatol 2010 Aug; 146:891.

5 The series was originally broadcasted by the BBC in 1986 .

6 See Updike, op.cit.

7 Couser, Th. Vulnerable Subjects: Ethics and Life Writing. Ithaca: Cornell University Press, 2004, p. 3 .

8 The results of the project were: an exhibition in Amsterdam (Gallery Melkweg, 2002) and a book (Elsevier Gezondheidszorg, 2002), in Dutch, that won a national award for the best book design of The Netherlands and an international award for the Best Book Design of the Year in 2002. Later on, the exhibition was re-designed as part of an exhibition on the history of dermatology in the Dutch National Museum for the history of science and medicine (Museum Boerhaave, Leiden, 2007).

9 For a film about the subject, made by Adrienne Norman in October 2015, please click https://vimeo.com/142909291. 